\title{
Um continente entortado (América Latina)
}

\author{
Kelly Hoffman e Miguel Angel Centeno \\ Tradução de Ana Paula Lima Rodgers
}

Tornou-se uma espécie de clichê notar que a América Latina é de longe a região mais desigual do mundo (cf. Berry, 1998; C ardoso e H elwege, 1992; 0 'D onnell e Tokman, 1998; Portes e H offman, 2003; Rosenthal, 1996; Prados de la Escosura, 2005). 0 nível de desigual dade encontrado no continente desafia a imaginação, bem como qualquer descrição ${ }^{1}$. Comparações transregionais são sempre difíceis, mas nenhum outro conjunto de países definido por quai squer critérios categoriais possíveis partilha tais características distribucionais. A faixa 5\% mais alta na escala de renda latino-americana recebe o dobro da porção comparável de suas contrapartes na 0 CDE (O rganização para a C ooperação eD esenvolvimento Econômico), enquanto a faixa mais baixa recebe a metade do que receberia naqueles mesmos países (cf. Portes e H offman, 2003).

As conseqüências desse sistema distributivo são ainda agravadas pelo fato de que, com algumas exceções significativas, essas sociedades são relativamente pobres². Assim, não apenas os pobres, os mais negros eas mulheres recebem fatias menores, mas o bolo social também não é grande, para início de conversa. A U N D P cal cula que mais da metade da população em vários países vive com menos de U \$ 2 (dois dólares) por dia. A Comissão Econômica para a América Latina eo $\mathrm{C}$ aribe das $\mathrm{N}$ ações $U$ nidas estima que mais de200 milhões vivem na pobreza (cf. O 'D onnell eTokman, 1998). 0 $\mathrm{H}$ aiti permanece no pior patamar, com um terço da população com expectativa de vida inferior a 40 anos (cf. G afar, 1998).

1. Várias organizações internacionais publicaram estatísticas confiáveissobre desigualdade, que são freqüentementeutilizadasem estudos da América Latina, os Indicadores de D esenvolvimento $\mathrm{M}$ undial do Banco M undial, a C omissão E conômica para a América Latina, a C omissão Econômica para a América Latina e 0 Caribe, o PanoramaSocial daAmérica Latinae os Indicadores de Desenvolvimento $\mathrm{H}$ uma no do Programadas $\mathrm{Na}$ ções U nidas para o De senvolvimento.

2. M edições dos níveis de pobreza são altamentecontenciosas. Em 
cinco diferentes estudos no M éxico em 1994, por exemplo, o nível de pobrezarelatado variava de $19,7 \%$ a $46 \%$. A medição da pobrezabaseizsefortementena definição enastécnicasestatísticasutilizadas, enão há ainda nenhum índice uniforme que seja amplamente aceito. Ver Lustig (1995) eM amalakis(1996).

3. Relação entre distribuição de renda e desenvolvimento econômico proposta por Simon Kusnetsem 1955, que tenta responder se a desigual dade na distribuição de renda aumenta ou diminui no decorrer do processo de crescimento econômico de um país. A relação configura-se como um " $U$ " invertido, em que a desigualdade de renda é crescente nos estágios iniciais da acumulação de capital, mas a partir de certo ponto se torna descrescente, e o produto continua a subir (extraído deSalvato et al., Crescimento e desigualdade: evidências da curva de Kusnes para os municípios de $\mathrm{M}$ inas $\mathrm{G}$ erais, 2006) (N.T.).
A combinação de pobreza e desigualdade faz da América Latina uma ilha onde grassa uma forma particular de miséria. O s latino-americanos vivem em condições piores do que poderiam: a correlação entre o PIB e o Índice de D esenvolvimento H umano do U N D P declina quando os países da América Latina são adicionados a uma amostra, indicando que os padrões de vida são piores do que as rendas nacionais poderiam prever. As evidências também indicam que uma parte significativa da miséria de uma grande porção da população não necessariamente origina-se na pobreza em si ou propriamente dita, mas, antes, nas conseqüências da distribuição radicalmente assimétrica (cf. Birdsall e Londoño, 1997).

0 queédesconcertante acerca da América Latina éque atémesmo a distribuição de sua má distribuição é desequilibrada: 0 índice de G ini para a faixa $90 \%$ mais pobre da população é comparável a países com o mesmo nível de desenvolvimento, mas éa concentração no decil mais rico que distancia a América Latina deoutras regiões (cf. PorteseH offman, 2003). Economistas relatam que a América Latina tem um "excesso de desigual dade"; se o nível de desigualdade fosse o mesmo encontrado em países com taxas comparáveis de desenvolvimento, a pobreza seria reduzida à metade (cf. Colburn, 1999).

0 crescimento reduz a pobreza, mas muito aquém do quese poderia esperar caso fossem mais baixos os níveis de desigual dade; o crescimento igualitário jamais existiu na América Latina (cf. Altimir, 1994). 0 sníveis demiséria e pobreza poderiam ser reduzidos mais substancialmente por meio de mudanças na distribuição do que pelo próprio crescimento (cf. Paes de BarroseM endonça, 1992). No caso do Brasil, por exemplo, o milagreeconômico do pós-guerra fez bem pouco para "atenuar a alta concentração de renda nas mãos da elite" (Wood e C arvalho, 1988, p. 3). A América Latina parece ganhar pouco em termos de crescimento econômico por conta dessa desigual dade (cf. Fields, 1992). A despeito da concentração deriquezanaArgentina, por exemplo, o investimento doméstico foi de $8 \%$ do PIB durante a maior parte dos anos de 1980 (cf. Cetragolo, 1997; Richards, 1997). É como se o país inteiro estivesse permanentemente na onda errada da curva de Kuznets ${ }^{3}$. A má distribuição não é um problema novo ou produto das últimas décadas (emboraas evidênciasindiquem que políticasneoliberais de fato contribuíram para aumentar a iniqüidade). A América Latina tem historicamente altos índices de desigual dade, mesmo durante o boom do pósguerra (cf. Altimir, 1997). D e 1950 a 1970, a industrialização e a urbanização criaram alguma mobilidade ascendente para partes significativas da 
população economicamente ativa (cf. O xhorn, 1998). D esde os anos de 1970, entretanto, cada um de seus países, à exceção da Colômbia nos anos de 1980 e do M éxico e da Venezuela nos anos de 1970, experimentou um aumento na concentração de renda e riqueza (cf. Altimir, 1994; Psacharopouloset al., 1995; Portes eH offman, 2003)4 ${ }^{4}$ H á pouca disponibilidadede números estatísticos quanto àrenda. Todas as evidências indicam quea concentração se apresentaria ainda mais desequilibrada caso incluíssemos também como parâmetro a riqueza. Em Santiago, a proporção deconsumo relativa ao quintil maispobreda população caiu 42\% de1969 a 1988, enquanto a do quintil mais rico cresceu em $23 \%$ (cf. Berry, 1998, p. 16). Rosenthal (1996) estima que, no começo da década de 1990, os $25 \%$ mais pobres sofreram uma erosão de mais de $10 \%$, mas os mais ricos ganharam $15 \%$. N o M éxico, a desigualdade aumentou desde a introdução do comércio livre. Entre 1984 e 1994, a renda absoluta dos 10\% mais ricos aumentou em $20,8 \%$, ao passo que a renda dos $10 \%$ mais pobres caiu em $23,2 \%$ (cf. Russell, 1997). O s coeficientes de Gini subiram em praticamente todos os países, deacordo com aU N D P eaC epal/Eclac. Além disso, os efeitos da má distribuição foram exacerbados pelas quedas econômicas. $\mathrm{N}$ a região como um todo, a renda per capita caiu de $10 \%$ a $11 \%$ durante os anos de 1980 (cf. Berry, 1998; Psacharopoulos et al., 1995). 0 colapso em alguns países foi quasebíblico: naArgentina, a porcentagem da população quevivena pobreza triplicou em uma única década, atingindo 29\% em 1990 (cf. Kaufman, 1997). Em Lima, o consumo médio familiar caiu em $55 \%$ durantea última metadedosanos de 1980 (cf. G lewweeH all, 1992). M edidas regionais globais de bem-estar social caíram em 15\% (cf. Altimir, 1997). Em São Paulo, 1,1\% da população vivia em favelas em 1970, contra 19,4\% em 1993 (cf. Caldeira, 1996).

O s verdadeiros níveis de pobreza, bem como os níveis individuais de desigualdade na região, com muita probabilidade são consideravelmente piores do que os indicados pelos números do consumo familiar citados acima, pois esses valores não dão conta do número de membros por família no mercado de trabal ho, negligenciando a tendência a uma crescente "autoexploração", em que uma porcentagem maior de membros de uma família trabalha por mais horas e depende de transações não monetárias (cf. Cortés, 1995a). Figueroa (1996) fala de um colapso no "equilíbrio distributivo" na América Latina, que desencadeia uma subseqüente desintegração da vida pública - o que produziu uma verdadeira onda de crimes em todas as cidades latino-americanas. A resposta da polícia tem sido brutal e está estreita-
4. M asver Fields (1992) para uma discordância quanto ao aumento da desigual dade. 
mente correlacionada à renda: em São Paulo, a polícia matou 1.470 civis em 1992, em contraste com os 25 mortos pelo $D$ epartamento dePolícia de Los Angeles (cf. Caldeira, 1996). A violência do cotidiano surge em variedades infinitas (cf. Scheper-Hughes, 1992). Em 1991, a violência era a principal causa de morte da população adulta dos bairros de classe operária de Buenos Aires, respondendo por mais de $30 \%$ de toda a mortalidade (cf. Arrossi, 1996).

0 grau de desigual dade encontrado na América L atina tem implicações muito concretas para a saúde e o bem-estar. A assistência à saúde varia consideravelmente entre os bairros numa mesma cidade. Em BuenosAires, a porcentagem da população sem cobertura de saúde vai de 19,5\% em bairros ricos a $40 \%$ em muitos bairros pobres, enquanto a porcentagem de residências sem vasos sanitários estende-se de menos de $2 \%$ a quase $17 \%$ da população. A mortalidade infantil é superior ao dobro em alguns bairros se comparada a áreas mais ricas (cf. Arrossi, 1996). Na Cidade do M éxico, a maior parte dos assentamentos irregulares de baixa renda não tem acesso convenienteà assistência pública de saúde, obrigando os pobres, em muitos casos, a pagar por assistências privadas. Em contraste, os bairros mais ricos são bem servidos em termos de instalações estatais de assistência à saúde (cf. Ward, 1987). Em M onterrey, no M éxico, mais de $90 \%$ dos domicílios nos bairros mais ricos têm água encanada e rede de esgoto. $\mathrm{N}$ os bai rros mais pobres, apenas $49 \%$ tem água encanada e só 35,3\% tem rede de esgoto.

O s dados de meados da década de 1990 em diante são esparsos e difíceis de analisar. O s mais otimistas indicam que o boom do começo da década de 1990 reduziu os níveis de pobreza em alguns (mas não todos) países, mas também produziu uma desigual dadeainda mai or (cf. KorzeniewiczeSmith, 2000; Sheahan, 1997). 0 Chile, por exemplo, experimentou um declínio significativo nos níveis de pobreza após a democratização (de 44\%, em 1988, para cerca de $20 \%$ uma década mais tarde), mas os níveis de desigualdade na verdade aumentaram durante esse período (cf. Vergara, 1997). A ArgentinaeaVenezuela, por outro lado, sofreram recentementecom quedas catastróficas no emprego e o crescimento da pobreza, eainda se encontram sobrecarregadas com uma distribuição derenda desigual, quepiorou duranteaúltima década. Ao longo de vinte anos, até 1995, a participação no consumo dos 30\% mais pobres em Buenos Aires caiu em 36\%, enquanto a do decil mais rico cresceu 44\% (cf. Auyero, 2000). O s salários nessa cidade caíram em $40 \%$ eastaxas depobreza cresceram em doisterços durantea década de 1990 (cf. Kessler, 1999). Talvez as transformações mais dramáticas te- 
nham ocorrido em Cuba, onde a reentrada do capital estrangeiro e a privatização de setores da economia criaram uma forma deapartheid do dóIar (cf. Centeno eFont, 1997; Tejada, 1994). U ma tendência éclara e praticamente universal na região: a erosão da classemédia (cf. C etrángolo, 1997; Grün, 1998; Kessler, 1999; M inujin, 1995; O 'D ougherty, 1999). D urante a década de 1980, o segundo e o terceiro quartil presenciaram quedas dramáticas em suas fortunas, em muitos casos perdendo $30 \%$ de sua renda (cf. M inujin, 1995). A Argentina é o caso extremo na emergência do que pode ser chamado de novos pobres. Em 1970, apenas 3\% dos residentes de Bue nos Aires eram pobres; o número aumentou para $20 \%$ em 1990 . N os últimos cinco anos, esse processo intensificou-se- fontes indicam quehojemetadeda população da grandeBuenosAires deveser ainda mais pobre.

Em muitos países, a resposta tem sido o derroti smo: um sentido de desesperança e uma regressão a críticas culturalistas que culpabilizam a América Latina por ter uma inclinação inerente ao fracasso (cf. M inujin, 1999). A companhando um ceticismo maisquecompreensível no potencial daação pública eem seus governos, um número significativo declasses profissionais juntou-se a seus conterrâneos mais pobres nas filas para obtenção de visto nas embaixadas da O ECD. Aqueles que permanecem buscam conforto em refúgiosfortificados, ondenão precisam interagir com a misériaà sua voltae ondeuma "estética da segurança" éanunciada como um "modo de vida pleno" (cf. Caldeira, 1996).

Os torturáveis e os não-torturáveis

0 que responde por esses níveis de desigual dade? 0 s padrões de posse da terra continuam medievais em todo o continente. Em praticamente todos os países, a elite agrária reteve o poder político e social em níveis profundos (cf. Conde, 1964), e a noção de um "colonialismo interno" se mantém relevante (cf. G onzález C asanova, 1970; Paige, 1997). N o Brasil, atéos anos de 1980,80\% da terra era ocupada em porções de cem hectares ou mais, enquanto propriedades de menos de dez hectares contabilizavam apenas 2,5\% (cf. Reynolds, 1996). M enos de $1 \%$ das posses da terra era de mais de mil hectares, mas elas respondiam por $43 \%$ da terra (cf. Wood e Carvalho, 1988). $\mathrm{Na}$ G uatemala, $85 \%$ das famílias rurais tinham carência de terra e 185 mil famílias não tinham terra al guma. Por outro lado, 2,3\% das fazendas ocupavam dois terços da terra cultivável (cf. Barillas, 1989). U ma exceção possível a essa tendência é o M éxico, que no século XX ope- 
5. A ruralização da pobreza também é responsável pelo fato de que, por muitos anos, as capitais dos países da América Latina puderam equiparar-se às suas contrapartes européias, enquanto a miséria escondia-se no campo. O s países latino-americanos sempre foram "misturas paradoxais de esplendor e decadência" (M ollenkopf e Castells, 1991, p. 8). rou a redistribuição formal de uma grande parcela da terra detida pela elite, sem que, no entanto, tenha havido uma queda subseqüente nos níveis gerais de desigual dade.

D urante os anos de 1970, os pobres concentravam-se nas áreas rurais. $\mathrm{D}$ ados do Brasil indicam queospioresníveis de desigual dadee condições de vida são encontrados nas áreas dominadas pela produção agrícola (cf. Leme e Biderman, 1997). Em 1980, 80\% dos pobres em alguns países viviam no campo (cf. Selowsky, 1981). O sníveis de miséria rural podem ter caído por causa das migrações maciças para as cidades durante os últimos quarenta anos. Astaxas de pobreza rural caíram 14\% entre 1970 e 1990, ao passo que as das cidades aumentaram em 30\% (cf. Rosenthal, 1996) ${ }^{5}$.

Pode-se falar também em bolsões de miséria disseminados pelo continente, os quais parecem resistir a todo e qualquer esforço no sentido de melhoria das condições. Talvez o mais vil desses casos seja o do Brasil: na década de 1980, havia uma diferença de 25 anos entre as expectativas de vida dos pobres no N ordeste edos ricosno Sul (cf. Wood eC arvalho, 1988; Scheper-H ughes, 1992). No subcontinente andino, que inclui as regiões em torno da cordilheira até o $M$ éxico, encontra-se um campesinato vivendo em apenas uma fração das porções disponíveis a suas contrapartes urbanas (cf. D ollfus, 1981).

As oportunidades de trabalho de qualquer tipo decaíram em todo 0 continente desde 1980 (cf. Franco e Di Filippo, 1998; Morley, 1995; Rosenthal, 1996; Sheahan, 1997). Buenos Aires, sozinha, perdeu 200 mil empregos durante os quatro primei ros anos da década de 1990 (cf. Altimir, 1997; Auyero, 2000), e é provável queatual mente o subemprego afete pelo menos um terço da população argentina. Os salários da América Latina permanecem baixos em comparação aos dos países desenvolvidos: são estimados em aproximadamente $30 \%$ dos custos de fabricação, em contraste com os 50\% na O ECD (cf. Reynolds, 1996). Todas as fontes relatam um declínio no nível dos salários disponíveis (cf. Rosenthal, 1996). A renda média da população ativa caiu em 40\% na Venezuela, 30\% em Buenos Aires e 21\% no Brasil (cf. M inujin, 1995). N a Argentina, em 1990, o salário mínimo reduziu-se para $40 \%$ daquele de 1980, e no Peru, para apenas 23\%. O s salários da indústria para esses países em 1990 eram, respectivamente, 78,7\% e 36,2\% dos valores de 1980, demonstrando a "pauperização do trabalho" (cf. Figueroa, 1996).

No que tange às variáveis individuais, a educação sempre foi um fator importante na determinação da renda, mais ainda no curso da última déca- 
da (cf. Altimir, 1997; Berry, 1998; Robinson, 1984). A distribuição da educação équasetão desequilibrada quanto a da renda. Ao compararmoso Brasil com osEstadosU nidos, por exemplo, defrontamo-noscom evidências de quehá - no primeiro - uma diferença muito maior nos níveis de escolaridade, bem como um maior retorno da educação (cf. Lam e Levison, 1992). Em 1980, 27\% dos brasileiros com mais de 35 anos não tinham nenhuma educação formal, enquanto outros $50 \%$ contavam com apenas quatro anos de estudos. $N$ ão é surpreendente, portanto, que os salários dos analfabetos alcancem apenas 6,5\% do valor daqueles que possuem nível superior de escolaridade (cf. Reynolds, 1996). Em 1990, 13,9\% dos mexicanos não tinha educação formal, e 57,3\% tinha seis anos de estudos ou menos. Os estados rurais de Zacatecas, $C$ hiapas $\mathrm{O}$ axacatinham a mais baixa média de tempo deescolaridade, quase 3,5 anosa menos do quena $\mathrm{Cidadedo} M$ éxico (cf. Bracho, 1995). 0 hiato entre as médias rural e urbana de alfabetização masculina é de cerca de 25,4 pontos percentuais na América Latina, e de 27,5 pontos percentuais entre as médias rurais e urbanas de alfabetização feminina (cf. Stromquist, 1990). A educação formal recebida por crianças da classe trabalhadora também tende a ser dequalidadeinferior. Ao mesmo tempo, as oportunidades educacionais para a classeal ta estão seexpandindo, criando um hiato ainda maior entre os pobres eos ricos (cf. I dem). Famílias ricas podem mandar seus filhos para escolas privadas, mas os filhos da classe trabalhadora freqüentam escolas públicas parcamente organizadas, reproduzindo as distinções de classe através das gerações (cf. Silva, 1998). N ão há dúvidas de que as duas últimas décadas também presenciaram o que um analista chamou de "viés regressivo" em termos de elaboração de políticas públicas (cf. Korzeniewicz e Smith, 1996; Rosenthal, 1996; H uber et al., 2006). Combinadas ao arrocho financeiro desencadeado pela crise de endividamento de 1982, essas pressões eliminaram o Estado como nivelador de último recurso. Isso aponta para um debate, que permaneceintenso, acerca do papel das políticas neoliberais no desenvolvimento da desigualdade na América Latina (cf. Berry, 1998; Birdsall e Graham, 2000; Izurieta e Vos, 1994; Korzeniewicz e Smith, 2000; Lustig, 1995; M orley, 1995; Trejos, 1992). H á poucas dúvidas de quea fraqueza do Estado tenha sido responsável por precipitar não apenas a falta de provisão de bens de consumo básicos, mas também um desequilíbrio na carga tributária. Aqueles que ganham menos que o salário mínimo destinam $37 \%$ de sua renda a impostos, enquanto os que ganham cem vezes o salário mínimo pagam menos de $13 \%$ (cf. Reynolds, 1996). Infelizmente, os países com os maiores desafios sociais 
são também aqueles que gastam menos em serviços (cf. Altimir, 1997). Grande parte do declínio na qualidade de vida da classe média pode ser explicada também pelo recuo do Estado em al gumas áreas, com um subseqüente declínio nos empregos e salários (cf. Berry, 1998). Na Argentina, os salários do setor público em 1991 reduziram-se a dois terços do que eram em 1980, e os professores ganhavam a metade dos salários da década anterior (cf. C etrángolo, 1997). "Retirar o Estado" quando ele não havia finalizado a sua tarefa principal acarretou conseqüências desastrosas para muitos (cf. Centeno, 1997; 2002).

A ascensão de políticas neoliberais esteve estreitamente ligada a uma maior integração da América Latina à economia mundial (cf. Goldfrank, 1999). H á uma longa tradição - embora hoje largamente desacreditada queatribui os problemas domésticos do continenteà sua posição internacional (cf. C ardoso eFaletto, 1978; G ereffi eFonda, 1992), mas há evidências dequeal guns aspectos do papel global daAmérica Latina contribuíram para um agravamento da crisena distribuição. A necessidadedenegociar adívida após 1982, por exemplo, pode ter levado al guns países a sinalizar sua "dureza" por meio da operacionalização de políticas regressivas (cf. Pastor e D ymski, 1991). Em todo caso, fluxos negativos de capital durante a maior parte dos anos de 1980 certamente enfraqueceram a capacidade dos governos demel horar a distribuição ou atenuar a pobreza (cf. Kaminsky ePerei ra, 1996). A busca por investimentostambém mexeu nabalançado poder entre trabal ho ecapital em prol do último (cf. Foweraker, 1997). A necessidadede proteger a economia da fuga de capital ou do recuo dos investimentos limitou severamentea escala eo escopo da ação do Estado.

Teoricamente, a integração do comércio deveria ter levado a reduções na distância entre os salários especializados e os não especializados (conforme ocorreu no Leste asiático), mas ela fal hou também nisso na América Latina (cf. Wood, 1997). Finalmente, e de modo mais conjectural, pode-se dizer quea vitória dos Estados U nidos nas revoluções sociais da América Central, combinada com o medo do retorno dos generais, estabeleceu claramente um limite que até mesmo os chefes de Estado mais progressistas não ousaram ultrapassar. Por outro lado, há claras evidências de que as pressões globais apoiaram o desenvolvimento dos direitos das mulheres e das minorias em geral (cf. Keck e Sikkink, 1998).

A nosso ver, nenhum modelo único dá conta de todos os padrões de desigual dade encontrados na América Latina, mas uma análise baseada no modelo declasses parece fornecer tanto a descrição maisacurada da situação 
quanto as explicações mais adequadas de suas causas. Seguindo o trabal ho dePortes (1985) esuas recentes atual izações (cf. Portes eH offman, 2003), a estrutura de classes latino-americana compreende os seguintes níveis:

- Uma "classe dominante" constituindo de 5\% a 13\% da população urbana conforme o país. Concentrada na capital, essa classe inclui pequenos e grandes empresários, burocratas de alto escalão, além de um diminuto número de pessoas nos postos de comando.

- A "pequena burguesia" de pequenos donos de lojas e microempresários, somando de $7 \%$ a $11 \%$ da população urbana. Esse tal vez seja o setor que mais foi afetado pela globalização, ou shoppinização, de muitas cidades.

- Um "proletariado formal", consistindo em 35\% a 40\% das populações urbanas, incluindo aqueles que trabalham em grandes fábricas e os que ocupam os cargos mais baixos do serviço público.

- 0 "setor informal", incluindo de $40 \%$ a $50 \%$ da população, no qual se destacam os donos de pequenas empresas ilegais, os trabal hadores dessas empresas e a massa de vendedores de rua e provedores de serviço sem nenhuma segurança ou proteção.

A essas categorias é preciso adicionar de $10 \%$ a $40 \%$ da população que viveno campo. M cK ay eVogt (1988) seccionam a estrutura declasses rurais em três grupos distintos: os aristocratas - a vel ha aristocracia fundiária - , as elites políticas e os abastados; os empresários, a classe de profissionais e comerciantes; e, por fim, os pobres, os quais são freqüentemente empregados no trabal ho braçal como serventes das duas classes mais altas. 0 s pobres, no estudo desses autores, incluem os empregados em empresas informais, assim como uma subclasse ainda mais pobre formada por aqueles de descendênciaindígena.

Conforme assinalamos, a característica mais distintiva da América Latina é a concentração dos recursos no topo relativamente diminuto da pirâmide. Pode-se dizer, de modo geral, que o decil mais rico apropria-se de não menos que metade da renda nacional, enquanto o centil mais rico detém a quase totalidade da riqueza. Essa situação é exacerbada pela existência do setor informal, no qual está concentrada a maior parte do crescimento empregatício (cf. Franco e D i Filippo, 1998). A concentração do poder no primeiro e da heterogeneidade no segundo tornou praticamente impossível organizar um programa político coletivista coerente, resultando freqüentemente em apelos populistas ilusórios que não fazem mais que 
reproduzir as mesmas estruturas de classe (cf. O xhorn, 1998; Chalmers et al., 1997).

Precisamente por causa dessas qualidades, cremos que a linguagem da análise de classes talvez seja inadequada para a América Latina. 0 tamanho dos desníveis que separam as seções da população, a ausência de qualquer tendência de longa duração para melhorar as injustiças e a estabilidade de uma população intocável de trabalhadores informais, tudo isso parece requerer categorias mais próximas do conceito de casta do que de classe. A coexistência de altos níveis de desigualdade com preconceito racial apóia essa categorização. Talvez o principal motivo para não usar a linguagem da análise de classes seja que, na era do pós-guerra e na O ECD, essas discussões tornaram-se associadas a uma noção de poder em termos não violentos e ocultos. Na América Latina, a desigualdade é apoiada por níveis de violência que remetem ao século XIX. Trata-se de uma desigualdade que só pode ser estabelecida e entendida por meio do constante, e diariamente reforçado, derramamento de sangue.

6. Recomendação usual dadaanovasesposasno M éxico.

\section{"Deixe sempre que ele coma primeiro" 6}

As condições das mulheres na América Latina mudaram significativamente ao longo do século XX. Barbieri (1983) discute três períodos nos quais os direitos das mulheres expandiram-se significativamente. 0 primeiro, de 1929 a 1962, centrou-se na obtenção de plenos direitos de cidadania concernentes à participação política e ao sufrágio. 0 segundo período, de 1945 até a atual idade, focal iza a expansão dos di reitos civis de propriedade e dos direitos ao pleno emprego. Finalmente, desdea década de 1970, assistimos à emergência de um movimento feminista na América Latina, preocupado com a igual dade plena entre os sexos nos âmbitos político, social e civil. O liveira (1997) examina as mudanças no trabalho feminino na segunda metade do século XX. Ela argumenta que, se de um lado a participação das mulheres no mercado de trabal ho cresceu, de outro, elas ainda permanecem em cargos ti picamente femininos eem muito menor número do que na Europa, América do N orte e partes da Ásia. A autora classifica o crescimento da participação das mulheres no mercado de trabalho em três períodos: sua emergência na força de trabalho durante as décadas de 1960 e 1970 - devido a mudanças sociais e demográficas; 0 aumento da sua participação no setor informal - como meio de sobrevivência familiar duranteas crises econômicas no começo da década de 1980; e sua crescente presença 
nas indústrias exportadoras e maquiladoras ${ }^{7}$, devido à globalização eà reestruturação econômica do final da década de 1980 até o presente.

O s teóricos da modernização acreditavam que o desenvolvimento conduziria naturalmente a uma melhora nas condições das mulheres, bem como a um incremento na sua participação no mercado de trabalho em particular. Entretanto, os resultados desse desenvolvimento não foram inteiramente positivos. Anderson e Dimon (1995) concluíram que 0 aumento de indústrias direcionadas à exportação conduziu, em certas re giões do M éxico, a um incremento da participação das mulheres no mercado de trabalho e uma redução da diferença de salários entre homens e mulheres. A despeito disso, e conforme atestam também esses autores, o mercado de trabal ho como um todo manteve-se largamente segregado em termos de gênero. A pesar da crescente participação das mulheres, D raper (1985) e D aza Samper (1997) argumentam que os empregos disponibilizados a elas em novas indústrias geralmente têm salários baixos e condições de trabalho ruins, com segurança limitada. Ademais, as empresas também tendem a preferir mulheres jovens, solteiras e sem filhos. D raper (1985) argumenta que o desenvolvimento do capitalismo na verdade minou o poder tradicional das mulheres no mercado de trabalho, ao reduzir a demanda pelo trabalho feminino na agricultura e na produção doméstica. D e modo semelhante, Labrecque (1998) avalia que, embora a globalização tenha atraído as mulheres para os trabal hos em manufaturas, isso não necessariamente traduziu-se em mudanças sociais. Ao contrário, esse fato tem implicado a ressurgência de um conservadorismo e a reação hostil contra mudanças nos papéis domésticos das mulheres.

A interseção entre classe e gênero desempenha um papel crucial nas experiências das mulheres que entram no mercado de trabalho (cf. Adler, 1994; D eere, 1995; Safa, 1995). G arcia de Fanelli (1991) aponta que muIheres de classe média, escolarizadas, têm mais chances de conseguir empregosdecolarinho-branco, com salários mais al tos, enquanto as pobresemenos educadas tendem a encontrar empregos no serviço doméstico e na indústria. W ilson (1998) sustenta que as mulheres que trabal ham no setor informal são em geral pobres casadas ou mães solteiras, e que até mesmo no setor informal elas costumam estar em desvantagem, pois têm uma rede de relacionamento menor e menos acesso ao capital. A autora afirma que as mulheres no setor informal sofrem de uma dupla exploração: de classe e de gênero. Segundo D el O Imo (1990), em seu estudo sobre mulheres e o tráfico ilegal de drogas, há uma significativa divisão do trabal ho em termos de
7. Indústrias manufatureiras de origem estrangeira situadas em território mexicano próximo à fronteira com os Estados Unidos, onde se produz a um baixo custo, utilizando mão-de-obra barata, produtos - desde ele trônicosaroupas- que irão ao Primeiro ou Terceiro M undoscomo importados dealto custo. (N.T.) 
gênero, com as mulheres na maioria das vezes realizando as tarefas marginalizadas até mesmo na produção e comércio de drogas ilegais. Além disso, elas correm mais riscos de exposição, porque grande parte do seu trabal ho é feito dentro de casa, onde é mais provável que a polícia execute mandados de busca e prisão.

U m argumento de grande difusão na literatura é que as condições das mulheres naAmérica Latina não mel horarão atéque se criem maiores oportunidades educacionais (cf. Campillo, 1994; D raper, 1985). Wainerman (1979) sustenta que a educação desempenha um papel bipartido ao inserir asmulheres no mercado detrabal ho. Em primeiro lugar, níveis maisaltosde educação possi bilitam oportunidades maiores deem pregosmais bem remunerados, ao mesmo tempo que fomentam o desejo entre mulheres instruídas de trabal har fora de casa. Em segundo lugar, a educação conduz a mudanças na estrutura das famílias e redefineos papéis domésticos femininosuma vez que estes últimos reduzem os limites da participação feminina no mercado de trabalho devido às responsabilidades familiares. Ao sustentar esse argumento, M arotz (1976) aponta que, na verdade, as famílias mexicanas têm aspirações mais altas para as suas filhas do que as famílias norteamericanas. Entretanto, essas aspirações não combinam com a realidade econômica a ser enfrentada por elas.

O utros estudos sustentam que há limites no papel que a educação desempenha no incremento das oportunidades econômicas para as mulheres. Segundo Cortina (1995), no M éxico, desde 1975, elas experimentaram um salto nos níveis educacionais, e meninas e meninos encontram-se representados igualitariamente nas escolas primárias e secundárias. Entretanto, os homensainda estão sobre representados na educação superior e, apesar desse incremento na educação, as mulheres permanecem concentradas em trabalhos tipicamentefemininos. Stromquist (1990) apresenta uma análise do alfabetismo, salientando os efeitos combinadosdeclasse, raça, regional idade e gênero nas oportunidades educacionais. Segundo ela, os níveis gerais de educação são al tos na América Latina, muitas vezes rivalizando com a Europa ea América do $\mathrm{N}$ orte. No entanto, a educação étambém altamente desigual. As mulheres apresentam índices de analfabetismo bem mais al tos que os homens, particularmente em áreas rurais, emais ainda as camponesas, as indígenas, as não-falantes de espanhol, faixa social na qual a diferença degê nero faz-sesentir profundamente. Segundo a autora, essas diferenças acarretarão importantes conseqüências para a desigualdade no futuro: à medida que novas oportunidades econômicas se abrirem para a população urbana, 
declasse média ealtamente instruída, as mulheres pobres do campo não terão condições deaproveitá-las.

A despeito das mudanças nas oportunidades econômicas para as mulheres, as mudanças sociaistêm sido bem maislentas. Segundo Allahar (1994), a condição social das cubanas melhorou bastanteapós a revolução, especialmenteem domínios públicoscomo acesso ao mercado detrabal ho eà educação (cf. também Smith ePadula, 1996). N ão obstante, no âmbito domiciliar elas permanecem as únicas responsáveis pelos deveres domésticos e pela reprodução da força de trabal ho. Segundo pesqui sadores dedicados ao estudo dadinâmicainterna dosdomicíliosno M éxico, particularmentedoscamponeses, estes possuem uma rígida divisão interna por gênero (cf. LeV ine, 1993). A análisedeStephen (1993) sobredomicílios ruraiszapotecas mostra quehomensemulheres têm atribuições muito diferentes, o queacarretaum ambiente marcado pela competição e pela luta de poder pelos recursos. Lawson (1998) argumenta que essas dinâmicas internas de poder têm conseqüências importantes sobre a migração, especialmente na determinação de qual membro da família vai migrar, e sobre as resultantes de tais estraté gias familiares. As contribuições econômicas das mulheres para a família são freqüentementen egligenciadas ou minimizadas, conseqüência das construções culturais de gênero (cf. Ehlers, 1990) ou da diferença de renda entre os cônjuges (cf. Paes de Barros et al., 2000). Além disso, há evidências empíricas suficientes que sugerem que os domicílios encabeçados por muIheres são mais suscetíveis ao risco de pobreza do que outros, e além disso, segundo Paes de Barrose M endonça (1992), apresentam maioresíndices de mortalidade infantil do que outras famílias. 0 s autores argumentam que essequadro éconseqüência da grandedi sparidadeentreos salárioseda estratificação ocupacional de acordo com a diferença de gênero. Chant (1997) ofereceuma explicação alternativa para essas avaliações. Elaargumenta, com basena observação de sua dinâmica interna, contraa idéia de quedomicílios encabeçados por mulheres são os mais pobres dentre os pobres. Segundo a autora, esses domicílios são os que mais provavel mente poderão contar com múltiplas fontes de renda, porqueas filhas terão aí mais chances de engajarse em um trabalho assalariado do que em domicílios encabeçados por homens. Em muitos casos as mul heres nessas famílias podem estar em melhorescondições por controlarem sozinhasa renda do lar.

É fato queas mulheresnaAméricaL atina são politicamenteativas, embora não tenham sido capazes de adquirir plena representação política e papéis deliderança. As formas de partici pação nas quais se engajaram abarcam des- 
deo envolvimento direto em eleições a movimentos mais amplos de mulhe res. Segundo Braun (1992), na Argentina, a participação das mulheres nas eleições é aproximadamente equivalente à dos homens, e em muitos casos atéexcede os níveis devotação masculinos. A autora também assinala quehá uma distância significativa entre as visões políticas de mulheres que trabaIham fora e as daquelas que se mantêm no âmbito dos papéis domésticos mais tradicionais. As primeiras tendem a assumir pontos de vista mais partidários da democracia e do pluralismo, sendo evidentemente muito menos defensoras deregi mesmilitares. No M éxico, segundo D alton (1990), asmuIheres da classe operária campesina foram oficialmenteincorporadas a sindicatos apoiados pelo Estado ea grupos políticos por meio de organizações governamentais de mulheres. Em Cuba, elas desempenharam historicamente um grande papel em movimentos políticos, inclusive na revolução de 1959. O Estado, por seu turno, promoveu a igual dadeem muitosâmbitosformais, como educação, emprego epartici pação política. Ainda assim, as dimensões culturais da desigual dade degênero mudaram muito mais devagar, permanecendo dominante, socialmente, uma definição tradicional dos respectivos papéis de gênero (cf. H arris, 1995; Rains eStark, 1997). Assim como Cuba, em toda a América Latina as mulheres executaram um importante papel nos movimentos políticos. D esde meados da década de 1970, o movimento feminista tem se envolvido ativamentena promoção direta da igual dade entre ossexos (cf. Alvarez, 1990, 1998; Stephen, 1997). M ovimentosdemulheres emergiram para lidar com outras preocupações políticas- especialmenteem âmbito local ena classe trabal hadora- , como "obter melhores serviços urbanos, protestar contra o alto custo de vida e ter acesso à assistência à saúde eà educação para seus filhos. Torturas, desaparecimentos e outras formas de re pressão política também uniram mulheres de todas as classes sociais na organização de movimentos pelos direitos humanos" (Sternbach et al., 1992, p. 401). Peña (1981) discute o papel das mulheres nas manifestações de classe nas maquiladoras. Guy (1998) traça a história de um predecessor desses movimentos, o M ovimento pelos D ireitos da C riança, o qual se centrava em questões acerca do bem-estar da criançae das mães da classeoperária. $\mathrm{H}$ oje, 0 movimento feminista tenta abarcar todas essas manifestações políticas etrabal ha para lidar com a complexidade de desigual dades de gênero, de classee deraça (cf. Vargas, 1992).

Apesar dos altos níveis de partici pação em eleições e movimentos políticos, e da inclusão oficial no governo do M éxico, o engajamento político de mulheres na América Latina mantém-se limitado. Rains e Stark (1997) 
enfatizam que as mulheres são quase totalmente excluídas dos papéis de liderança no governo cubano. Atitudes tradicionais também continuam representando barreiras para a agenda do movimento feminista. Sternbach et al. (1992, p. 402) afirmam que, mesmo atualmente, os movimentos de mulheres vêem-se "continuamente admoestados contra a adoção de 'más' crenças feministas, tais como 0 direito ao aborto e o direito à autodeterminação sexual". Embora encontremos altos níveis de participação política entre as mulheres latino-americanas, o movimento feminista ainda tem um longo caminho pela frente antes de chegar à igual dade de gênero.

"Quem não é branco é preto"

Seseguirmoso trabal ho desenvolvido pela equipedo Banco M undial (cf. Ferranti, 2004), queremetea um amplo consenso naárea, torna-sesuficientemente claro que no âmago da desigual dade da América Latina aloja-se a divisão racial, produzida pela Conquista e pela subseqüente escravização de populações africanas. Esse sistema de exclusão racial não se mantém apenas como barreira explícita para a mobilidade social e como um dispositivo para a exploração, mas, antes, o legado histórico das castas raciais permeia quase todas as relações e estruturas sociais. 0 u seja, para entender a desigual dade naAmérica Latina épreciso focar nasquestões raciais. Essecontinentehíbrido é composto por pelo menos três tradições étnicas, que produzem uma série infinita de variações de cores e culturas. Por muitos anos, persistiram mitosacerca deumademocracia racial na região: deum Brasil perfeitamente harmonioso racialmente, que combina as tradições ibéricas e africanas; de uma mestiçagem, de novas raças, conceitos que supostamente evitavam categorias anglo-americanas mais duras. $M$ as a realidade racial na América Latina é, evidentemente, bastante diferente (cf. D e la Fuente, 2001; Reichmann, 1999; Safa, 1998; Sherif, 2001; Twine, 1997; Wade, 1993; W inant, 1994). A Venezuela talvez seja o único grande país da região onde os nãobrancos desempenham papéis significativos na política nacional (cf. Sansone, 1998). A desesperança por seser pobreenegro no Brasil ou a indignidade sofrida pela classe média indígena dos Andes não são menos reais porque emergiram de um padrão de conquista e escravidão diferente daquele dos Estados U nidos (cf. Andrews, 1991; Pereña, 1992; Scott, 1985; Stone, 1990; Viotti da C osta, 1994).

E, de fato, a América Latina assemelha-se aos seus vizinhos do norte pela persistência de um debate a respeito da relativa significação da raça em 
contraposição à classe na determinação do status social, além de um debate equivalente acerca das bases materiais da identidade em oposição às interpretações culturalistas ou pós-modernas. $\mathrm{N}$ ão há dúvidas de que a "clivagem de privilégio e oportunidade segue distinções étnico-raciais" (Portes, 2001, p. 229), mas concordamos com H ale (1997), que considera boa parte desse debateno mínimo improdutiva. Aquilo queScheper-H ughes (1992) chama de "a economia política do sofrimento" resiste a esforços para evitar as complicações de contexto e de história na definição de categorias que predestinam os miseráveis.

Para entender a dinâmica da desigualdade racial na América Latina, é crucial avaliar duas diferenças significativas com relação às sociedades do norte. Em primeiro lugar, categorias bi polares são relativamente inúteis na maioria das situações na América Latina (cf. Safa, 1998). Evidentemente, há um abismo enorme entre os brancos ou europeus e aqueles que não 0 são, mas essas categorias são difusas e moldadas pelo contexto (cf. Portes, 1984; Wade, 1997). Tampouco raça e etnicidade são necessariamente percebidas como categorias biológicas. Sem dúvida, al guns fenótipos são mais desejáveis que outros (como o demonstra uma passada de vista superficial pela televisão latina), mas eles não são nem necessários nem suficientes para a categorização racial. A identidade étnica é, em parte, resultado da posição de classe, da localização geográfica e de estratégias individuais, mas é também um meio para "expressar e perseguir coletivamente interesses, demandas e valores" (H ale, 1997, p. 517).

As origens dos grupamentos raciais na América Latina não são claras. Segundo M arx (1996; 1998), certas categorias refletem a extensão do consenso da elite à época da formação das nações. $D$ adas a homogeneidade e a coesão dessas elites latino-americanas no século XIX, elas não sentiram necessidade al guma de criar sistemas formais de exclusão como meio de consolidar sua posição. Jimeno (1989) também argumenta que categorias raciais são criação das polícias estatais, mas aqui a ênfase estána "minorização" daquilo que é, na verdade, a maioria da população.

Em alguns casos, os Estados decidem abolir categorias raciais, recusando-se a reconhecer al gumas real idades. 0 Estado equatoriano partedo princípio de que todos os cidadãos são metiç̧os, posição legal que acaba por obscurecer as origens da dominação (cf. D e la Torre, 1999). A raça cósmica no M éxico é um construto similar, mas, na realidade, al guns são mais raça do que outros. A ideologia da mestiçagem tem sido utilizada, em muitas instâncias, como apoio para uma política de "branqueamento" da massa 
indígena (cf. Q uijada, 1998; Rahier, 1998; Safa, 1998). D a mesma forma, a criação de um camponês genérico obscurece as realidades e as identidades raciais, como no caso de Porto Rico, Cuba e República D ominicana (cf. Safa, 1998). Esses mitos são supostamente corroborados por estatísticas, evocadas para conferir-Ihes legitimidade. Entre 1890 e 1940 o Brasil não coletou dados raciais em seu censo, e em 1961 Fidel Castro decretou que Cuba estava livre do preconceito, de modo que a partir de então nenhum dado censitário racial foi disponibilizado. A pesar dessas estratégias oficiais, o drama da raça é com freqüência experimentado individualmente, com a mobilidade e 0 engano onipresentes: "O s limites étnicos de grupos são mantidos e manipulados [...] não tanto pelos mitos raciais, mas por uma sel eção local de real idades e mitos ligados à concatenação de fatores sociais, culturais, políticos eeconômicos, os quais variavam por meio de... tempo e espaço" (Belote e Belote, 1984, p. 25).

O Brasil permanece 0 caso mais relevante para os estudiosos norteamericanos da desigualdade. Em 1914, Theodore Roosevelt declarou que nesse país não havia nenhuma barreira racial (cf. Reichmann, 1999), algo que jamais correspondeu nem corresponde à realidade. Ali, a definição de raça, tanto naquela época quanto agora, é assaz diversa da encontrada nos Estados Unidos. Jamais houve, por exemplo, uma regra do tipo da one drop rule ${ }^{8}$ no Brasil (cf. Fry, 2000; Skidmore, 1995; W inant, 1992). 0 país teve, contudo, uma experiência significativa com o racismo científico (cf. Stepan, 1991). Ali, cor é a categoria chave: em um censo de 1991, os entrevistados utilizaram cem palavras diferentes para descrever sua raça (cf. Reichmann, 1999). D aniella Fernandes lista 127 categorias diferentes na década de 1980. A ambigüidade da identidade racial foi vista, por muitos anos, como uma "válvula de escape" que permitia a mobilidade nãobranca (cf. Andrews, 1992; 1993), ao passo que outros viram a supremacia de classe como "dinheiro embranquecido" (cf. Guillebeau, 1999). Essa ambigüidade não refletia igualdade, mas uma persistente tendência social a escapar da negritude.

Sherif (2001) documenta como os brasileiros usam a linguagem tanto para discriminar como para negar seu preconceito. E, maisqueisso, todasas evidências indicam que, embora a grande divisão seja entre os brancos e os não-brancos, os pardos têm mais vantagens do que os negros mais escuros; assim, poucos brasileiros escolhem reconhecer esta identidade, preferindo um processo de automulatização. Isso conduz também a um debate considerável sobre as condições reais da população não-branca, dependendo dos
8. Regra segundo a qual, em alguns estados americanos, era preciso apenas uma gota de sangue negro para uma pessoa ser legalmente considerada um afro-norte-americano (N.T.). 
termose das definiçõesutilizados (cf. H arris et al., 1993; Telles, 1995; Telles eLim, 1998). No entanto, não há dúvidas dequea raça seja um componente significativo da desigual dade no Brasil (cf. Aguiar, 1994). Ambigüidades raciaistambém tornaram muito mais difícil construir quaisquer políticas de ação afirmativa (cf. Fry, 2000; G uillebeau, 1999; G uimarães, 2002, 2005). D esde os estudos pioneiros empreendidos pela U nesco na década de 1950, tem-setornado cada vez mais clara a divisão racial no Brasil; há poucas dúvidas de que distribuição de renda e empregos refletem a hierarquia social da cor (cf. H asenbalg, 1994). N a média, os brancos vivem sete anos mais, têm um quarto a mais de chances de sobreviver na infância, sua taxa de conclusão da escola secundária é quatro vezes maior e têm metade das chances de serem presos (cf. Fry, 2000; Lovell eW ood, 1998). Já os afro-brasileiros têm $42 \%$ a mais de probabilidade de serem vítimas de assalto (cf. M itchell e Wood, 1999). As diferenças de salário entre homens brancose não-brancos se mantêm mesmo quando são levados em conta fatores como a escolaridade ea experiência profissional (cf. Lovell eD wyer, 1988, p. 136; Skidmore, 1995). Até mesmo em categorias ocupacionais idênticas, os não-brancos ganham de 50\% a 75\% dos salários dos brancos (cf. Andrews, 1992, 1993; Reichmann, 1999). É desanimadoraa diferença deganhosdebrancosenãobrancos, que aumenta à medida que se sobe na escada ocupacional (cf. Andrews, 1992, 1993; H asenbalg, 1994). De forma semelhante, Telles (1992; 1994; 1995) encontra maior segregação racial nos bairros mais ricos do Rio de Janeiro do que nas zonas mais pobres. Enquanto há favelados de todas as cores (embora com tendência a serem mais escuros), a elite émuito mais homogeneamente branca (cf. Twine, 1997).

A situação dos negros em outras partes da América Latina não é melhor (cf. W hitten e Torres, 1998). N o Equador, o surgimento de uma beleza negra como vencedora de um concurso causou um escândalo (cf. Rahier, 1998); G afar (1998) relata que nos países caribenhos com populações africana e indígena mais significantes (Trinidad e Tobago e Guiana) há uma grande distância entre as raças, com os descendentes de indígenas no topo. Cuba é, juntamente com o Brasil, o país onde a composição racial mais se assemelha à dos Estados U nidos e tem sido objeto de considerável atenção (cf. De la Fuente, 1998, 2001; D ominguez, 1976; Ferrer, 1999; H elig, 1995; M oore, 1988). A despeito de mitos semel hantes àqueles encontrados no Brasil, há claras evidências de significativas desigualdades raciais anteriores a 1959, refletidas em renda, educação, saúde, residência e encarceramento. H ouve muitos esforços para desafrancesar os afro-cubanos e para 
lidar com quaisquer movimentos políticos, particularmente os oriundos do exército expressivamente negro da independência. Tanto quanto no Brasil, empregaram-se esforços para criar uma identidade nacional que evitava a raça. $\mathrm{H}$ á um debate considerável a respeito de se essa identidade só serviu para obscurecer a dominação (cf. H elig, 1995) ou se também funcionou como uma defesa significativa contra políticas ainda mais discriminatórias (cf. D e la Fuente, 2001). Se, de um lado, as políticas sociais da revolução melhoraram claramente os padrões de vida dos afro-cubanos, de outro, a sua representação nos círculos políticos dirigentes permanece extremamente limitada, o mesmo acontecendo no âmbito da cultura popular, a qual se mantém extremamente racialista, senão racista. $\mathrm{H}$ á também uma considerável ansiedadena ilha quanto à sobrevivência das mel horias nos padrões de vida no caso de uma transição pós-C astro.

As condições dos herdeiros das culturas pré-colombianas são paralelas àquelas dos descendentes de escravos. Talvez haja uma ambigüidade maior ainda nas categorias que envolvem a "indianidade". Primov (1980), por exemplo, contrasta as percepções eas reivindicações de identidade dos indígenas de Sierra com as dos amazônicos. $N$ as terras altas andinas, a categoria índio passou a referenciar tanto uma categoria de classe como uma categoria étnica, mas na Amazônia ela ainda implica autonomia ea existência de um mundo social diferente. Similarmente, no M éxico, ladinos eíndios podem até concordar com o fato de que os primeiros sejam socialmente dominantes, mas, enquanto os ladinos sustentam que essa posição se deve a características a eles atribuídas, os índios vêem-na como conseqüência do poder econômico (cf. Aguilar, 1979).

No M éxico e nos Andes, categorias étnicas originaram-se das classificações racistas do século XVI, mas evolveram para al go muito mais complicado (cf. N utini, 1997). A confusão entre índios, ladinos, cholos e mestiços em geral não tem nada a ver com fenótipos, mas com vestuário, local de nascimento ou residência e linguagem?.

$\mathrm{N}$ ão obstante, como no caso dos negros no Brasil, à medida que se sobe no sistema de estratificação a significância de sinais culturais recua e a do fenótipo aumenta. A mobilidade ascendenteéfluida e possível, mas permanece caracterizada pelas vantagens de uma brancura racial. $\mathrm{H}$ á uma considerável lacuna nas estatísticas sobre a população indígena atual, até mesmo nos países com um grande número de não-brancos (cf. Gomez-Perasso, 1976). No entanto, não há dúvidas de que existem fortes relações causais entre etnicidade, educação e renda (cf. Dillon Soares e Reyna, 1967). M es-
9.É importante notar que cada um desses termos é considerado depreciativo por aqueles situados um grau acima na cadeia social. 
10.Frase dita por um morador de uma favela de Buenos Aires, citado em Auyero (2000, p. 15). mo quando adquirem altos status ocupacionais, os não-brancos acumulam menos dinheiro e são tratados diferentemente.

Essas mesmas ambigüidades dasidentidades têm frustrado esforços para criar políticas "pró-índio" (cf. Beaucage, 1988; Swepston, 1978). Há uma ênfase pública paradoxal tanto na integração como na preservação cultural (cf. Banton, 1996). As diferenças entre indigenismo e indianidade preenchem debates acadêmicos (cf. Berdichewsky, 1986). O s esforços para criar uma ideologia do camponês genérico em geral fracassaram. Recentemente, entretanto, a ascensão de movimentos sociais e políticos indígenas em vários países indica que as estruturas do poder étnico podem estar mudando (cf. H arvey, 1998; Lucero, 2001; Turner, 1996; Warren, 1998; Yashar, 1999).

"O futuro não é o que costumava ser" 10

Começamos nossa discussão com a trilogia marshalliana dos direitos civis, políticos e sociais, e admitimos que nos concentraríamos nos últimos. N o século XXI, é impossível negar a importância dos direitos políticos e as conseqüências de eles serem abreviados. Com relação aos direitos civis, alguns comentadores recentes focal izaram o queG uillermo 0 'D onnell chama de "a morenização da sociedade" eas conseqüências para todosos aspectos da vida quando instituições legais são corroídas. $\mathrm{N}$ ão obstante, tomando em consideração a desigualdade difusa e penetrante que documentamos na América Latina, é difícil imaginar como os direitos políticos e civis podem ser construídos de forma realista nesse continente sem que se abordem primeiramentealgumas desuascontrapartessociais. 0 problema para qualquer tomador de decisão na A mérica L atina équeesses direitos sociaistêm poucas chances de ser implementados sem uma democracia para demandá-los etribunais para defendêlos. 0 dilema para a América Latina é ter de construir simultaneamente um conjunto de direitos que muitas vezes se contradizem uns aos outros.

Antes de considerar quai squer opções futuras, os estudiosos da América Latina têm de se perguntar por que a desigualdade é tão penetrante no continente. Poder-seia até mesmo dizer que a desi gual dade éa característica essencial, constante e definidora da região. R espira-se desigualdade por toda a parte na América Latina, ao ponto de sua permeabilidade chegar, muitas vezes, a impedir estudiosos e residentes de enxergá-la. A injustiça torna-se tão normalizada que a idéia de um mundo sem ela é impossível, o que corrobora a tentação de responsabilizar a simples reprodução histórica 
como a causa principal. N o entanto, ao contrário de casos como o pré-1994 na África do Sul ou o J im C row ${ }^{11}$ nos estados sulinos norte-americanos, não há instituições formais para as quais se possa apontar como diretamente responsáveis e contra as quais se possa lutar. N esse sentido, sociedades latino-americanas podem assemel har-se aos paradigmas do dilema liberal clássico: a ausência de restrições formais à liberdade ajuda a constranger a liberdade individual de escolha. A ascensão de Lula da pobreza à presidência do Brasil também indica que a mobilidade social é possível.

$\mathrm{N}$ otamos a ausência de qual quer coisa que se aproximasse de um corpus coerente detrabal hosteóricossobre a desigual dadena região, e, segundo entendemos, esse subdesenvolvimento deve-se, em grande medida, à ausência deesforçossistêmicos de coleta de dados. Isso retardou astentativas deanalisar melhor as cau sas e as conseqüências tanto da pobreza como da desigualdadena região; as metodologias e definições de conceitos básicos variam por país, cidade e estudo. Um problema significativo para o teste das relações discutidas acima têm sido as limitações de dados em âmbito nacional. U ma comparação subnacional que leve em consideração atributos de governos provinciais elocais auxiliaria em uma melhor indicação do papel do Estado na promoção da desigualdade resistente. Fazem-se igualmente necessários estudos domiciliares em diferentes países, para que se possa verificar as consequêencias cotidianas das estruturas sociais latino-americanas. Isso só pode ser feito por meio dos mesmos tipos de levantamentos amplos e precisos le vados a cabo pela OECD. Insistimos fortemente na necessidade de uma aliança de interesses entrea comunidade sociológica interessada na estratificação e a comunidade de acadêmicos latino-americanistas, a qual, decerto, encorajaria o desenvolvimento de uma estratégia de pesquisa regional que incluísse um amplo levantamento com amostra domiciliar de múltiplos anos. Somente de posse detal instrumento poderemos começar a mapear as condiçõesno continentecom as devidas precisões padronizadas para a elaboração de estudos. 0 estudo do Banco M undial, de2003, éum excelenteprimeiro passo (cf. Ferranti, 2004). A questão não é puramente de ordem acadêmica: sem essas análises, é impossível determinar em que extensão a injustiça tão prevalente no continenteé uma função da cultura, da história ou da economia política. Sem uma resposta, qual quer esperança de identificar esses problemas torna-se natimorta.

Com relação às diretrizes teóricas, para explicar o padrão latino-americano da desigual dade é preciso identificar fatores que satisfaçam duas condições: em primeiro lugar, deve ser um fator singular a essa região do mundo;

11. Referência às Jim Crow Laws, leis segregacionistas que vigoraram entre 1876 e 1967 nos estados do Sul dos Estados Unidos. Uma de suas principais determinações foi o estabelecimento de lugares separados para negrose brancos em locais públicos, como trens e ônibus, eescolas(N .T.). 
em segundo lugar, devemos encontrar, dentro da América Latina, uma correlação positiva entre o grau em que tal fator aparece e o nível de desigualdade. $\mathrm{D}$ a discussão acima, três possibilidades destacam-se das demais.

D evemos, em primeiro lugar, reconhecer o passado excepcionalmente longo da América Latina como colônia e seu desenvolvimento subseqüente no contexto de um sistema global. Em segundo, devemos também estar prevenidos quanto ao impulso viciante de culpabilização do outro, hábito demuitosnaAmérica Latina. A posição dedependência estrutural do continente em um mercado global tem sérias conseqüências para a distribuição dos bensedo poder. Isso ainda éfato hoje, quando os constrangimentoseas demandas impostos às sociedades daA mérica Latina por credores, organizações financeiras internacionais emercados de capitais globais tornam difícil até mesmo a manutenção de Estados assistencialistas mínimos.

Em que medida a dependência externa ajuda a explicar as desigual dades no continente? Essa questão tem sido relegada, muito freqüentemente, a polêmicas, na pior das hipóteses, ou a histórias de casos isolados, na melhor delas. Por exemplo, as evidências indicam que o fato de a Costa Rica ter evitado tornar-se um produtor significativo de um importante artigo de exportação exerceu um papel fundamental no desenvolvimento maisigualitário verificado nesse país (cf. M ahoney, 2001; Paige, 1997). Por outro lado, a Argentina e o U ruguai foram membros ativos do mercado global e ainda assim construíram as classes médias mais alargadas da América Latina. 0 que precisamos são medições concretas de posições estruturais em diferentes pontos no tempo, que permitam uma avaliação sistêmica do efeito desse fator em desenvolvimentos subseqüentes. Precisamos reconhecer eanalisar mais a fundo as conseqüências da abertura de mercado de capitais e a crescente dependência definanciamentosinternacionais, ecomo tudo isso limitou a ação estatal.

D eve-se implementar uma estratégia si milar para que se possa comparar o destino da América Latina com o de outras regiões no último quarto do século XX. D evemos certamente analisar mel hor o quanto as políticas neoliberais contribuíram para piorar os níveis de desigualdade. Também aqui há argumentos teóricos e evidências empíricas de ambos os lados. D evemos investigar se e por que a implementação dessas políticas na América Latina produziu um maior crescimento da desigual dade do que em outras regiões do mundo. Devemos também ser capazes de melhor discernir entre as políticas neoliberais (por exemplo, privatização versus abertura de mercado), de modo a poder medir os diferentes efeitos das mesmas sobre o continen- 
te. Também será necessário que distingamos entre os ganhadores e os perdedores sociais. $\mathrm{N}$ ão resta nenhuma dúvida de que, enquanto alguns setores sociais se beneficiaram das medi das neoliberais, outros pagaram um alto preço por elas. Esses efeitos devem ser quantificados de modo que se possa chegar a alguma avaliação reagregada, talvez até mesmo excessivamente utilitária, das amplas conseqüências das novas políticas.

No contexto do sistema global, a América L atina destaca-se por manter uma estrutura social praticamente prémoderna, composta pela casta dos absurdamentericos em seu topo ea maioria numérica não integrada na base. A forma interna de colonialismo é o segundo componente crítico de uma explicação da desigual dadelatino-americana. $N$ essesentido, argumentamos por um estudo mais profundo das significações relativas de raça, classee gênero, e suas interações com uma desigual dade geral. Embora certamente as distinções e as hierarquias étnicas não sejam exclusividade da América L atina, diríamosqueo continenteémarcado por um sistema de preconceito racial particularmente uniforme e resistente, que contribuiu para moldar as distinções de classe. Conforme notamos, o termo casta encontra bastante aplicabilidade ao continente. Combinado a esse legado de propriedade territorial produzido pelaC onquista, isso criou uma superposição delimites hierárquicos, tornando qualquer tipo de mobilidade social praticamente inimaginável. C omo observou M ahoney em trabalho recente (cf. M ahoney, 2003), a relação entre desigual dade e composição étnica também é muito forteno continente.

A magnitude cabal das iniqüidades torna as distinções associadas aos estudos clássicos norte-americanos sobre estratificação não muito atraentes ou aconsel háveis. M ais que procurar por al guma hierarquia causal, sustentamos que há, no mínimo, uma clara interação cumulativa entre raça, gêne ro, classe e regionalidade. Em suma, ser negra, mulher, desempregada e residente no N ordeste do Brasil é ser pega em tantas armadilhas estruturais que se torna quase impossível escapar.

Q uanto ao nosso terceiro fator, sugerimos que há uma correl ação negativa, segundo medi ções variadas, entre a capacidade estatal e a desi gual dade (com a direção causal correndo para ambos os lados). 0 nde autoridade política e sistemas burocráticos foram mais bem estabelecidos, a capacidade dosque se encontram na base de insistir em melhores medidas de bem-estar aumentou. A pesar de sua reputação de Leviatã, a capacidade dos Estados da América Latina de fazer qual quer coisa que seja é muito limitada. As recenteseleições no Brasil eno Equador ajudarão a indicar em quemedida grupos 
12. Estamos sugerindo a relação oposta àquela proposta por D eSoto. Para ele, o Estado dominador empurra as pessoas para ainforma lidade. Para nós, apenas um Estado ineficaz responde pelo tamanho de tal setor. políticos comprometidos com uma maior eqüidade social poderão usar instrumentos políticos para melhorar a situação. Será um acidente, por exemplo, que, à exceção deM éxico eCuba (ede- menosengajadamente- Chilee Peru), a América Latina ainda esteja à espera de uma maciça redistribuição agrária, como aconteceu em outras zonas de desenvolvimento similar? U ma vez mais, arelação entreo poder institucional daautoridade políticaea desigual dade parece ser significativa nos países no continente. Cremosquea ausência do Estado, ou ao menos de um que tenha condições e vontade de abordar as disfunções sociais, também éum fator responsável pelas instituições peculiares encontradas da América Latina. Talvez não esteja mais na moda depender do Estado, mas, se as pessoas desejam mudar a sociedadee eliminar as barreirasàcidadania plena, édifícil imaginar como isso seriafeito sem poder político. 0 Estado norte-americano deu direitosaos trabal hadores, eliminou a segregação, garantiu a aposentadoria e construiu estradas. A fal hadaAmérica Latina em fazer o mesmo, ou melhor, em fazêlo no mesmo nível, permitiu um mercado hobbesiano em que vidas demais são ruins, brutais ecurtas.

A informalidade econômica está ligada também à noção de capacidade estatal ${ }^{12}$. Em alguns países, o setor informal chega a ser responsável por metade da população economicamente ativa. $N$ esses casos, mudanças em qualquer direção nos salários oficiais podem ter pouco significado para a qual idade de vida da população como um todo. $\mathrm{N}$ a ausência de um Estado, a economia informal representa um conjunto permanente de miseráveis e marginalizados.

$\mathrm{Na}$ ausência de um Estado, os ricos podem manter suas posições por meio da prática da violência brutal. Como notamos, os estudos sobre a desigualdade em países desenvolvidos freqüentemente podem ignorar as cruas imposições de poder que caracterizam relações desiguais. $\mathrm{N}$ a América Latina, o poder tem uma face clara, não se esconde atrás de muitas fachadas institucionais. 0 poder pode ser visto no assassinato de dissidentes e de líderes sindicais, bem como nas chacinas de meninos de rua. $M$ ais recentemente, também pode ser visto na eterna ameaça da transferência de fundos para paraísos fiscais. Esse poder nem mesmo precisa ser exercido. É a própria ameaça da violência ou da transferência de capital que com freqüência torna inviáveis muitas políticas. A chave para o entendimento de como se faz política na América Latina parece ser "não provocar a direita". Enquanto asforças que se beneficiam da não-distribuição social mantiverem esse veto, a desigual dade permanecerá onipresente. 


\section{Referências Bibliográficas}

Adler, H ellman J. (1994), M exican lives. N ova York, N ew York Press.

Aguiar, N euma. (1994), Rio de Janeiro plural. Rio de Janeiro, Rosa dos Tempos.

Aguilar, J. L. (1979), "Class and ethnicity as ideology: stratification in a M exican town". Ethnic Groups, 2 (2): 109-131.

Allahar, A. L. (1994), "Women and the family in Cuba: a study across time". H umboldt Journal of SocialRelations, 20 (1): 87-120.

Altimir, O . (1994), "Cambios de la desigualdad y la pobreza en la América latina”. El Trimestre Económico, 61 (241): 85-133.

. (1997), "D esigualdad, empleo y pobreza en América L atina: efectos del ajuste y del cambio en el estilo de desarrollo". Desarrollo Económico, 31 (145): 3-30.

Alvarez, S. E. (1990), Engendering democracy in Brazil: women'smovementsin transition politics. Princeton, NJ, Princeton U niversity Press.

. (1998), "Feminismos latinoamericanos". Revista Estudos Feministas, 6 (2): 265-284.

ANderson, J. B. \& D IM ON, D . (1995), "The impact of opening markets on M exican male/female wage and occupational differentials". Social Science Journal, 32 (4): 309-326.

Andrews, G. R. (1991), Blacks and whites in Sao Paolo, 1888-1988. M adison, University of Wisconsin Press. . (1992), "Racial inequality in Brazil and the U nited States: a statistical comparison". Journal of Social H istory, 26 (2): 229-263.

. (1993), "D esigualdad racial en Brasil y en los Estados U nidos: un estudio estadístico comparado". D esarrollo E conómico, 33 (130): 185-216.

Arrossı, S. (1996), "Inequality and health in the metropolitan area of Buenos Aires". Environment and U rbanization, 8 (2): 43-70.

Auyero, J. (2000), Poor peoplés politics: peronist survival networks and the legacy of Evita. D urham, D uke U niversity Press.

Banton, M. (1996), "International norms and Latin American states' policies on indigenous peoples". Nations and Nationalism, 2 (1): 89-103.

Barbieri, M. T. de. (1983), "Políticas de población y la mujer: antecedentes para su estudio". Revista M exicana de Sociología, 15 (1): 293-308.

Barbieri, T. de. (1997), "Cambios en la situación de la mujer". D emos, 10: 32-33.

Barillas, E. et al. (1989), "Formación nacional y realidad étnica en Guatemala". América Indígena, 49 (1): 101-129.

Beaucage, P. (1988), "La condición indígena en M éxico". Revista M exicana de Sociología, 50 (1): 191-211. 
Belote, L. S. \& Belote, J. (1984), “D rain from the bottom: Individual ethnic identity change in Southern Ecuador". Social Forces, 63 (1): 24-50.

BerdicheWSKY, B. (1986), “D el indigenismo a la indianidad y el surgimiento de una ideología indígena en andinoamérica”. América Indígena, 46 (4): 643-658.

Berry, A. (1987), "Poverty and inequality in Latin America”. Latin American Research Review, 22 (2): 202-214.

(org.). (1998), Poverty, economic reform, and income distribution in Latin America. Boulder, C O, Lynne Reinner.

Birdsall, N . \& Graham, C. (2000), N ew markets, new opportunities?: Economic and social mobility in a changing world. Washington, DC, Bookings Institute.

BIRdSALL, N. \& LONDOÑo J. L. (1997), Asset inequality does matter: Iessons from Latin America. OCE Working Paper 344. Washington, DC, Inter-American Development Bank.

Bracho, T. (1995), "D istribución y desigualdad educativa en M éxico". Estudios Sociológicos, 13 (37): 25-53.

Braun M . (1992), "Political attitudes of women in the Southern Cone". D esarrollo Económico, 31 (124): 565-577.

Caldeira, T. P. R. (1996), "Fortified enclaves: the new urban segregation". Public Culture, 8 (2): 303-328.

Campillo, F. (1994), "Género, comunicación y desarrollo". Chasqui, 49: 65-66.

Campos, J. \& H ugarte, R. P. I. (1973), "M igrantes de clase baja en Buenos Aires". Revista Paraguaya de Sociología, 10 (27): 101-117.

Cardo so, F. H . \& Faletto, E. (1978), D ependency and development in Latin America. Berkeley, University of California Press.

Cardoso, E. \& Helwege, A. (1992), "Below the line: poverty in Latin America". World D evelopment, 20 (1): 19-37.

Centeno, M . A. (1997), Democracy within reason: technocratic revolution in M exico. University Park, Pennsylvania State University Press. . (2002), Blood and debt: war and the N ation-State in Latin America. University Park, Pennsylvania State University Press.

Centeno, M. A. \& Font, M. (orgs.). (1997), Toward a new Cuba?: Legacies of a revolution. Boulder, CO, Lynne Rienner.

Centeno, M. A. \& López-Alves, F. (orgs.). (2001), The other mirror: grand theory through the lens of Latin America. Princeton, NJ, Princeton U niversity Press.

Cetrángolo, O . (1997), "Structural adjustment and public-sector pay in Argentina, 1975-91". Studies in D evelopment Economics, 8: 135-158.

Chalmers et al. (orgs.). (1997), The new politics of inequality in Latin America: rethinking participation and representation. $\mathrm{N}$ ova York, O xford U niversity Press. 
Chant, S. (1997), "Women-headed households: Poorest of the poor? Perspectives from M exico, Costa Rica and the Philippines". IDS Bulletin, 28 (3): 26-48.

Colburn, F. D. (1999), "Inequality in Latin America”. Dissent, 46 (3): 26-29.

CONDE, R. C. (1964), "Cambios estructurales y clases sociales en la crisis política argentina". Foro Internacional, 5 (17): 27-37.

Cortés, F. (1995a), "Procesos sociales y demográficos en auxilio de la economía neoliberal: un análisis dela distribución del ingreso en M éxico durantelos ochenta". Revista M exicana de Sociología, 57 (2): 73-90.

. (1995b), "El ingreso de los hogares en contextos de crisis, ajuste y estabilización: un análisis de su distribución en M éxico, 1977-1992". Estudios Sociológicos, 13 (37): 91-108.

CortinA, R. (1995), "La educación de la mujer en Latinoamérica: la profesión de la enseñanza en M éxico". Estudios Sociológicos, 13 (39): 595-611.

Dalton, M . (1990), "La organización política, las mujeres y el Estado: el caso de 0 axaca". Estudios Sociológicos, 8 (22): 39-65.

Daza Samper, M. L. (1997), "An international division of labor: gender and the information technology industry". International Journal of Politics, Culture and Society, 10 (4): 635-658.

De la Fuente, A. (1998), "Race, national discourse, and politics in Cuba: an overview". Latin American Perspectives, 25 (3): 43-69.

. (2001), A nation for all: race, inequality, and politics in Twentieth Century Cuba. Chapel Hill, University of N orth Carolina Press.

D E LA TORRE, C. (1999), "Everyday forms of racism in contemporary Ecuador: the experiences of M iddle-Class Indians". Ethnic and Racial Studies, 22 (1): 92 112.

Deere, C. D. (1995), "W hat difference does gender make? Rethinking peasant studies". Feminist Economics, 1 (1): 53-72.

D EL O LM O, R. (1990), "The economic crisis and the criminalization of Latin American women". Social Justice, 17 (2): 40-53.

Dillon Soares, G. A. \& Reyna J. L. (1967), "Raza y clases sociales en M éxico". Ciencias Políticas y Sociales, 13 (48): 201-220.

D ollfus, O . (1981), “D es paysanneries minoritaires”. Études Rurales, 81-82: 5-24.

D om Inguez, J. I. (1976), "Racial and ethnic relations in the Cuban armed forces: a non-topic". Armed Forces and Society, 2 (2): 273-290.

D raper, E. (1985), "Women's work and development in Latin America”. Studies in Comparative International D evelopment, 20 (1): 3-30.

EhLERS, T. B. (1990), “D ebunking marianismo: economic vulnerability and survival strategies among Guatemalan wives". Ethnology, 30 (1): 1-16. 
FerrantI, D avid M. de (org.). (2004), Inequality in Latin America: breaking with H istory?. Washington, World Bank.

Ferrer, A. (1999), Insurgent Cuba: race, nation, and revolution, 1868-1898. Chapel $\mathrm{H}$ ill, University of N orth Carolina Press.

Fields, G. S. (1992), "Changing poverty and inequality in Latin America". Public Finance, 47: 59-76.

FigueroA, A. (1996), "The distributive issue in Latin America”. International Social Science Journal, 48 (2): 231-244.

Foweraker, J. (1997), "C apital, power and inequality in Latin America". Journal of Latin American Studies, 29 (3): 788-789.

Franco, R. \& DI FILIPpo A. (1998), “G lobalización, integración regional y equidad social en América Latina". Revista Paraguaya de Sociología, 35 (101): 7-20.

Fry, P. (2000), "Politics, nationality, and the meanings of 'race' in Brazil". D aedalus, 129 (2): 83-118.

Gafar, J. (1998), "Poverty, income growth, and inequality in some C aribbean countries". Journal of Developing Areas, 32 (4): 467-490.

Garcia de Fanelli, A. M. (1991), "Empleo femenino en la Argentina: de la modernización de los '60 a la crisis de los '80". D esarrollo Económico, 31 (123): 395-414.

GerefFI, G. \& Fonda, S. (1992), "Regional paths of development". Annual Review of Sociology, 18: 419-448.

G LEWWE, P. \& H ALL, G. (1992), Poverty and Inequal ity during unorthodox adj ustment: the case of Peru, 1985-1990. Washington, DC, The World Bank.

Goldfrank, W. L. (1999), “Global restructuring, employment, and social inequality in urban Latin America". Journal of Interamerican Studies and World Affairs, 41 (2): 146-149.

Gomez-Perasso, J. A. (1976), "Contexto socioeconómico del indio en el Paraguay oriental". Revista Paraguaya de Sociología, 13 (37): 37-48.

González Casan ova, P. (1970), D emocracy in M exico. N ova York, O xford University Press.

Grün, R. (1998), "A classe média no mundo do neoliberalismo". Tempo Social, 10 (1): 143-163.

Guillebeau, C . (1999), "Affirmative action in a global perspective: the cases of South Africa and Brazil". Sociological Spectrum, 19 (4): 443-465.

Guim arães, Antonio Sérgio. (2002), Classes, raças e democracia. São Paulo, FU SP/ Editora 34. . (2005), Racismo e anti-racismo no Brasil. São Paulo, FU SP/Editora 34.

GuY, D. J. (1998), "The politics of Pan-American cooperation: maternalist 
feminism and the child rights movement, 1913-1960". Gender \& H istory, 10 (3): 449-469.

H ALE, C. R. (1997), "Cultural politics of identity in Latin America”. Annual Review of_Anthropology, 26: 567-590.

H ARRIS, C. (1995), "Socialist societies and the emancipation of women: the case of Cuba". Socialism and Democracy, 9 (18): 91-113.

H ARRIS, M . et al. (1993), "W ho are the whites? I mposed census categories and the racial demography of Brazil". Social Forces, 72 (2): 451-462.

H ARVEY, N . (1998), TheChiapas rebellion: thestrugglefor land and democracy. D urham, N C, D uke University Press.

H asen balg, C. (1994), "Perspectivas sobre raza y clase en Brasil". Estudios SociológiCos, 12 (34): 75-99.

. (1995), "Entre o mito e os fatos: racismo e relações raciais no Brasil". D ados, 38 (2): 355-374.

H ELIG, A. (1995), O ur rightful share: the Afro-Cuban struggle for equality, 1886-1912. Chapel $\mathrm{Hill}$, University of $\mathrm{N}$ orth Carolina Press.

H uber, Evelyne et al. (2006), "Politics and Inequality in Latin America and the C aribbean". Comunicação apresentada na Reunião da Lasa.

Izurieta, A. \& Vos, R. (1994), "Ajuste estructural y costo social en la América Latina: ¿Q ué nos explican los estudios recientes?". El Trimestre Económico, 61 (241): 27-84.

J Imeno, M . (1989), "Conflicts and strategies of Latin American ethnic minorities". Current Anthropology, 30 (2): 264-265.

Kaminsky, G. L. \& Pereira, A. (1996), “The debt crisis: Lessons of the 1980's for the 1990's'. Journal of Development Economics, 50 (1): 1-24.

Kaufman, R. (1997), The next challenges for Latin America. Instituto Juan M arch, Working Paper 108. M adrid, Instituto Juan M arch deEstudios e Investigaciones.

KECK, M. \& SIKKINK, K. (1998), Activists beyond borders: advocacy networks in international politics. Ithaca, NY, Cornell University Press.

KeSSLER, G. (1999), "L'experience de pauperisation de la classe moyenne argentine". Cultures \& Conflicts, 35: 71-93.

Korzeniewicz, R. P. \& Smith, W. C. (orgs.). (1996), Latin America in the world economy. Westport, CT, Praeger.

. (2000), "Poverty, inequality, and growth in Latin America: searching for the high road to globalization". Latin American Research Review, 35 (3): 7-54.

Labrecque, M . F. (1998), "Women and gendered production in rural Yucatan: some local features of globalization". U rban Anthropology, 27 (2): 233-262.

Lam, D. \& Levison, D. (1992), "Age, experience, and schooling: decomposing 
earnings inequality in the U nited States and Brazil". Sociological Inquiry, 62 (2): 220-245.

Lawson, V. A. (1998), "H ierarchical households and gendered migration in Latin America: feminist extensions to migration research". Progress in H uman Geography, 35 (101): 61-78.

Leme, M . C. \& Biderman, C. (1997), “O mapa das desigualdades no estado de São Paulo". Novos Estudos Cebrap, 49: 181-211.

LEVINE, S. (1993), D olor y alegría: women and social changein urban M exico. M adison, University of Wisconsin Press.

Lodoño, J. L. (1996), Poverty, inequality, and human capital development in Latin America, 1950-2025. Washington, DC, The World Bank.

LovelL, P. A. \& D wYeR, J. W. (1988), "T he cost of being nonwhite in Brazil". Sociology and Social Research, 72 (2): 136-142.

LovelL, P. A. \& W OOD, C. H. (1998), "Skin color, racial identity, and life chances in Brazil". Latin American Perspectives, 25 (3): 90-109.

Lucero, J. A. (2001), "Crisis and contention in Ecuador". Journal of D emocracy, 12 (2): 59-73.

LustiG, N . (org.). (1995), Coping with austerity: poverty and inequality in Latin America. Washington, DC, The Brookings Institute.

M AHoney, James. (2001), "Path dependence, historical lock-in, and the legacy of colonialism in Spanish America". M anuscrito. . (2003), "Long-run development and the legacy of colonialism in Spanish America". The American Journal of Sociology, 109 (1): 50-106, jul.

M Am ALAKIs, M. J. (1996). "Poverty and inequality in Latin America: mesoeconomic dimensions of justice and entitlements". Journal of Interamerican Studies and World Affairs, 38 (2-3): 1-13.

M arotz, R. (1976), "Sex differentiation and inequality: a M exican-U nited States comparison of parental aspirations for daughters". Journal of Comparative Family Studies, 7 (1): 41-53.

M ARX, A. W. (1996), "Racemaking and the nation-state". World Politics, 48 (2): 180.

(1998), M aking race and nation: a comparison of the U nited States, South Africa and Brazil. Cambridge, Cambridge University Press.

M CKAY, C. \& VOGT, E. Z. (1988), "Some contours of social class in a Southern Mexican Town". Ethnology, 27 (1): 27-44.

M InUjIN, A. (1995), "Squeezed: the middle class in Latin America". Environment and U rbanization, 7 (2): 153-165.

M INUJin, A. (1999), "¿La gran exclusión? Vulnerabilidad y exclusión en América 
Latina". In: FILm Us, D. (org.), Los noventa: política, sociedad y cultura en América Latina y Argentina de fin de siglo. Flacso/Eudeba, pp. 53-77.

Minujin, A. \& Kessler, G. (1995), La nueva pobreza en la Argentina. Buenos Aires, Planeta.

M itchell, M. J. \& W OOD, C. H . (1999), "Ironies of citizenship: skin color, police brutality, and the challenge to democracy in Brazil". Social Forces, 77 (3): 10011020.

Moore, C. (1988), "Race relations in socialist Cuba". In: Roca, S. (org.), Socialist Cuba: past interpretations and future challenges. Boulder, CO , Westview, pp. 175206.

M ollenkopf, J. \& Castells, M. (eds.). (1991), Dual city: restructuring N ew York. N ova York, Russell Sage Foundation.

M ORLEY, S. A. (1995), Poverty and inequality in Latin America: theimpact of adjustment and recovery in the 1980s. Baltimore, M D, Johns H opkins U niversity Press.

N UtinI, H. G. (1997), "Class and ethnicity in Mexico: somatic and racial considerations". Ethnology, 36 (3): 227-238.

O 'D onnelL, G. \& T o Km An, V. (orgs.). (1998), Poverty and inequality in Latin America. $\mathrm{N}$ otre Dame, IN , U niversity of N otre Dame Press.

O 'D ougherty, M. (1999), "The devalued state and nation: neoliberalism and the moral economy discourse of the Brazilian middle class, 1986-1994". Latin American Perspectives, 26 (104): 151-174.

O livelRA, O . de. (1997), "M ultiple analytic perspectives on women's labor in Latin America". Current Sociology, 45 (1): 109-119.

O XHORN, P. (1998), "The social foundations of Latin America's recurrent populism: problems of popular sector class formation and collective action". Journal of $\mathrm{H}$ istorical Sociology, 11 (2): 212-246.

Paes de Barros, R.; Henrique R. \& Mendonça, R. (2000), “D esigualdade e pobreza no Brasil: retrato de uma estabilidade inaceitável". Revista Brasileira de Ciências Sociais, 15 (42): 123-142.

Paes de Barros, R. \& M endonça, R. (1992), “A research note on family and income distribution: the equalizing impact of married women's earnings in metropolitan Brazil". Sociological Inquiry, 62 (2): 208-219.

PAIGE, J. M . (1997), Coffee and power: revolution and the rise of democracy in Central America. Cambridge, $\mathrm{H}$ arvard University Press.

PAstor, M . \& D YM SKI, G . A. (1991), “D ebt crisisand class conflict in Latin America”. Capital Class, 43: 203-231.

PeñA, D. G. (1981), "Las maquiladoras: M exican women and class struggle in the border industries". Aztlán, 11 (2): 159-229. 
Peralta Ramos, M . (1992), The political economy of Argentina: power and class since 1930. Boulder, CO, Westview.

Pereña, L. (1992), Genocidio en América. M adrid, Editorial Mapfre.

PoRTES, A. (1984), "T he rise of ethnicity: determinants of ethnic perceptions among Cuban exiles in M iami". American Sociological Review, 49 (3): 383-397. . (1985), "Latin American class structure: their composition and changeduring the last decades". Latin American Research Review, 20 (3): 7-39. . (2001), "Theories of development and their application to small countries".

In: Chase-D unn, C.; Jon As, S. \& Am ARo, N . (orgs.), Globalization on the ground. Lanham, M D, Rowman \& Littlefield, pp. 229-240.

PoRTEs, A.\& H ofFm AN, K. (2003), "Latin American class structures: their composition and change during the neoliberal era". Latin American Research Review, 38 (1): 41-82.

Prados de la Escosura, Leandro. (2005), "Growth, inequality and poverty in Latin America: historical evidence, controlled conjectures". M adrid, U niversidad C arlos III. Working Paper 05-41 (04), Economic H istory and Institutions Series.

Prim ov, G . (1980), "C lass, amerindian ethnicity and economic development". Ethnic and Racial Studies, 3 (3): 342-354.

Psacharo poulos, G. et al. (1995), "Poverty and income inequality in Latin America during the 1980's". Review of Income and Wealth, 41 (3): 245-264.

Q UIJADA, M . (1998a), "La question indienne". Cahiers Internationaux de Sociologie, 105: 305-323. . (1998b), "Presentation". Cahiers Internationaux de Sociologie, 105: 301-303.

RAHIER, J. M . (1998), "Blackness, the racial/spatial order, migrations, and M issEcuador 1995-96". American Anthropologist, 100 (2): 421-430.

Rains, R. H . \& Stark, A. E. Bopp. (1997), "The role of women in Cuba: Cuban women's equality in the context of articles 24-28 of the family code enacted in 1975". Social Development Issues, 19 (2-3): 71-86.

Ramos, J. R. (1996), "Poverty and inequality in Latin America: a neostructural perspective". Journal of Interamerican Studies and World Affairs, 38: 141-157.

ReICHMAnN, R. (1999), Race in contemporary Brazil: from indifference to inequality. University Park, Pennsylvania State University Press.

Reynolds, L. G. (1996), "Some sources of income inequality in Latin America". Journal of Interamerican Studies and World Affairs, 38 (2-3): 39-46.

RichaRdS, D. G. (1997), "Inflation, unemployment and distributional conflict in Argentina, 1984-90". Journal of Development Studies, 34 (2): 156-172.

RobINSON, R. V. (1984), "Reproducing class relations in industrial capitalism". American Sociological Review, 49 (2): 182-196. 
Rosenthal, G. (1996), "On poverty and inequality in Latin America”. Journal of Interamerican Studies and World Affairs, 38(2-3):15-37.

RusseLL, J. W. (1997), “M exico's rising inequality”. M onthly Review, 49 (7): 28-33. SAFA, H . I. (1995), T he M yth of the M ale Breadwinner. Boulder, CO , Westview. . (1998), "Introduction". Latin American Perspectives, 25 (3): 3-20.

Sansone, L. (1998), "Racismo sem etnicidade. Políticas públicas e discriminação racial em perspectiva comparada”. D ados, 41 (4): 751-783.

Scheper-H ughes, N. (1992), D eath without weeping: the violence of everyday life in Brazil. Berkeley, University of C alifornia Press.

Sсотт, R. J. (1985), Slave emancipation in Cuba: the transition to free labor, 18601899. Princeton, N J, Princeton University Press.

Selowsky, M . (1981), "Income distribution, basic needs and trade-offs with growth: the case of semi-industrialized Latin American countries". World D evelopment, 9 (1): 73-92.

SHEAHAN, J. (1997), "Effects of liberalization programs on poverty and inequality: Chile, M exico, and Peru". Latin American Research Review, 32 (3): 7-37.

Sherif, R. E. (2001), D reaming of equality: color, race, and racism in urban Brazil. N ew Brunswick, NJ, Rutgers U niversity Press.

Silva, F. C. de. (1998), "C hile: la incorporación de la mujer al mercado del trabajo. ¿Panacea del crecimiento económico?". Estudios Latinoamericanos, 5 (9): 163-181.

SKIDM ORE, T. E. (1995), "Fact and myth: discovering a racial problem in Brazil". In: Goldscheider, Calvin (ed.), Population, ethnicity, and nation-building. Boulder, C O, Westview Press, pp. 91-117.

SM IARO SKI, M . S. (1996), "Women and changes in Chilean economy: some questions". Gender and Development, 4 (3): 22-28.

Smith, L. M. \& Padula, A. (1996), Sex and revolution: women in socialist Cuba. N ova York, Oxford University Press.

SMITH, W. C. \& KorzenieWicz, R. (orgs.). (1997), Politics, social change, and economic restructuring in Latin America. Coral Gables, FL, North-South Center.

Stepan, N. (1991), The hour of eugenics: race, gender, and nation in Latin America. Ithaca, Cornell U niversity Press.

Stephen, L. (1993), "Gender and class in Zapotec households". Anthropology of Work Review, 13-14 (4-1): 5-8.

. (1997), Women and social movements in Latin America: power from below. Austin, University of Texas Press.

Sternabch, N. S. et al. (1992), "Feminisms in Latin America: from Bogotá to San Bernardo". Signs, 17 (2): 393-434. 
Stone, S. Z. (1990), Theheritage of the conquistadores. Lincoln, U niversity of N ebraska Press.

Strom quist, N . P. (1990), “Literacy and women in Latin America”. N ew Education, 12 (2): 31-39.

SwEPston , L. (1978). "The Indian in Latin America: approaches to administration, integration, and protection". Buffalo Law Review, 27 (4): 715-756.

Szekely, M iguel. (1996), "T heresources of poverty: women and survival in a M exican City". Journal of Latin American Studies, 28 (1): 260-261.

Tejada, A. A. (1994), "Cuba: efectos sociales de la introducción de la lógica del mercado". Estudios Latinoamericanos, 1 (2): 131-141.

Telles, E. E. (1992), "Residential segregation by skin color in Brazil". American Sociological Review, 57 (2): 186-197. . (1994), "Industrialization and racial inequality in employment: the Brazilian example". American Sociological Review, 59 (1): 46-63. . (1995), “W ho are the morenas?". Social Forces, 73 (4): 1609-1611.

Telles, E. E. \& Lim, N . (1998), "D oes it matter who answers the race question? Racial classification and income inequality in Brazil". D emography, 35 (4): 465-474.

Trejos, R. A. (org.). (1992), Ajuste macroeconómico y pobreza rural en América Latina. San José, Instituto Interamericano de Cooperación para la Agricultura.

T urner, T. (1996), "Brazil: indigenous rights vs. neoliberalism". Dissent, 43 (184): 67-69.

T WINE, F. W. (1997), Racism in a racial democracy: the maintenance of white supremacy in Brazil. New Brunswick, NJ, Rutgers University Press.

VARGAS, V. (1992), "The feminist movement in Latin America: between hope and disenchantment". D evelopment and Change, 23 (3): 195-214.

Vergara, P. (1997), "In pursuit of 'growth with equity': the limits of Chile's freemarket social reforms". International Journal of Health Services, 27 (2): 207-215. V IотTI DA C OSTA, E. (1994), Crowns of glory, tears of blood: the demerara slave rebellion of 1823. N ova York, Oxford University Press.

W ADE, P. (1993), Blacknessand race mixture: thedynamics of racial identity in Colombia.

Baltimore, M D , Johns H opkins University Press. . (1997), Race and ethnicity in Latin America. N ova York, Pluto Press.

W ain erman, C. H . (1979), "Education, family and economic participation in Argentina". D esarrollo Económico, 18 (72): 511-537.

W ARD, P. (1987), "Reproduction of social inequality: access to health services in M exico City". H ealth Policy and Planning, 2 (1): 44-57.

W ARren, K. B. (1998), Indigenous movements and their critics. Pan-M aya activism in Guatemala. Princeton, NJ, Princeton University Press. 
Whitten, N. E. \& Torres, A. (orgs.). (1998), Blackness in Latin America and the Caribbean. Bloomington, Indiana University Press.

W ILSO N, T. D . (1998), "Approaches to understanding the position of women workers in the informal sector". Latin American Perspectives, 25 (2): 105-119.

W in Ant, H. (1992), "Rethinking race in Brazil". Journal of Latin American Studies, 24 (1): 173-192.

. (1994), Racial conditions. politics, theory, comparisons. M inneapolis, U niversity of M innesota Press.

W olden berg, J. (1997), "Racismo y educación". Revista M exicana de Ciencias Políticas y Sociales, 42 (167): 153-160.

Wood, A. (1997), "O penness and wage inequality in developing countries: the Latin American challenge to East Asian conventional wisdom". TheWorld Bank Economic Review, 11 (1): 33-57.

Wood, C. \& Carvalho, J. A. M agno de. (1988), The demography of inequality in Brazil. Cambridge, C ambridge University Press.

YASHAR, D. J. (1999), "D emocracy, indigenous movements, and the postliberal challenge in Latin America". World Politics, 52 (1): 76-104.

\section{Resumo}

Um continente entortado (América Latina)

Em todo o mundo, a América Latina é a região que apresenta a mais desequilibrada distribuição de recursos. 0 artigo define um conjunto comum de elementos que caracterizam as estruturas sociais do continente, sugere algumas linhas de análise e teorização e defende a integração dos estudos regionais nas discussões mais amplas a respeito da estratificação. N a primeira parte, examina-se a situação do continente como um todo, com uma breve discussão sobre a relação entre pobreza e desigualdade, e sobre o problema da disponibilidade de dados. Em seguida, analisa-se classe, gênero e raça. A conclusão identifica três fatores críticos que explicam a desigual dade latinoamericana: sua posição no interior do sistema econômico global, o colonial ismo interno que mantém as categorias raciais e o subdesenvolvimento das estruturas estatais. Palavras-chave: Classe; G ênero; Raça; Estratificação comparada.

\section{Abstract}

The lopsided continent (Latin America)

Latin America has the most unbalanced distribution of resources of all regions in the world. This review defines a set of common elements characterizing social structures on this continent, suggests some approaches for analysis and theorizing, and supports the integration of regional studies into broader discussions of stratification. An 
overview of the situation on the continent as a whole, including a short discussion of the relationship between poverty and inequality, allows to address some concerns with data availability. We then devote a section each to class, gender, and race, and conclude by identifying three critical factors that explain Latin American inequality: its position within a global economic system, internal colonialism with maintenance of racial categories, and the underdevelopment of state structures. Keywords: Class; Gender; Race; C omparative stratification.

Kelly $\mathrm{H}$ offman e $\mathrm{M}$ iguel Angel Centeno são professores do Departamento de Sociologia da Universidade dePrinceton. E-mails: khoffman@princeton. edu; cenmiga@prince ton.edu. 